\title{
Internships Abroad: The View from Paris
}

\author{
G e r a I d H o n i g s b I u m \\ Boston University
}

\section{A F e B uzz Words}

In addition to the term "computerization," two other words vie for highest frequency usage in current educational discourse: "internationalization" and "professionalization." The sum total of these two terms could arguably equal "internships abroad.” Whether we talk about recruitment of teachers and students to American campuses or sending our students and teachers into myriad overseas educational programs, these two concepts stand today as accurate barometers of our universities' institutional strategies. The following observations result from eleven years of experience in the field, more specifically in France, a setting that raises particularly challenging and probing questions. France ranks high among the nations most resistant to deregulation as well as strong on cultural exception, endowed with a combative attitude about the supremacy of the French language, and nurtured by a checkered relationship with America and its hegemony: no two countries compete more earnestly in their respective attempts to influence the world. Some two million French students serve as interns as part of their education. No other European country comes anywhere near this statistic.

\section{Overview of a National Labor Scene}

The words stage and stagiaire in French are high frequency terms in daily conversation. The work place, already under strong pressure to adjust to the thirty-five-hour work week, regularly dispatches its employees-stagiaires on frequent retraining sessions making the work place even 
more stressful than it was before. Students in professional schools have long included an internship as an integral part of the curriculum. Today the public universities crumbling under the yoke of open admissionalmost all lycéens get the sacrosanct bac- have become what critics call "parkings à chômage," unemployment holding tanks. This cynical view of university life in France is not encouraging. Calendars and curricula are changing slowly in response to the requirements of emerging, modern, multinational corporations. One way administrators have been able to respond was to encourage French students to obtain internships in order to get a pragmatic sense of professional life, and to fill the excessive free time on their hands. The mechanism is well in place, as is a well-honed rhetoric about internships and the issuance of the "convention de stage," a binding liability insurance document certifying that the intern is a registered, degree-seeking student. Without this document, co-signed by the school, the business, and the intern, a student cannot be a stagiaire. That rule applies to foreign students, and schools or businesses that work around it run the risk of major liability. The intern may be paid the standard one-third of minimum wage, or may be non-paid. In some cases, depending on the level of expertise and company policy, the student may receive a more generous reward (never called a salary), or in-kind support in the form of monthly commuting passes, lunch vouchers, or a company product.

Suffice it to say that the internship market in France is saturated and consequently far more competitive than was the case just a few years ago. Given the current economic climate, companies have announced hiring freezes or have laid off employees. Bringing in interns must be carefully viewed as part of the company's educational mission, in keeping with the call of redefining business ethics along the lines of the "entreprise-citoyenne." Still the presence of interns is carefully watched by union and ministry inspectors to make certain that profit making is not just the result of cheap labor. Small companies cannot easily sustain the high benefits packages involved in hiring personnel and often operate to a significant extent with the help of interns. But that too is a mixed blessing and becomes an object of controversy. Finally, the paradox of the vacation-prone French and the surprisingly high level of productivity attributed to France by OCDE statistics result in an even more puzzling mosaic of the national labor scene. 


\section{Anticipating an Internship Abroad}

Such is the background against which a Paris-bound student enrolls in an internship program, of course, unbeknownst to the young person who has been anticipating that semester in one of the world's most beguiling capitals. How to prepare for an optimal and genuine academic, cultural, personal, and pre-professional experience is the joint responsibility of a number of individuals. These include, first, the students who want to extend their learning beyond their campus community and who make an important conceptual leap into unfamiliar territory; the parents, who are concerned about their offspring's safety and who must trust their level of maturity and the institutional resources to make the experience rewarding and advantageous; and the faculty, who want to make certain that the internship is going to feature adequate data gathering, guided observation, faculty mentoring, and, most importantly, appropriate analysis to warrant the academic credit hours the college or university may grant.

Meeting the expectations of one and all is a difficult challenge. Dovetailing pre-professional experience abroad and academic respectability is an urgent issue. All institutions at the very least implicitly require that the internship be the object of intellectual inquiry. A growing number of these institutions are explicit about the level of that inquiry. Concomitantly, what is the prevailing ethos that many of our young people come with? What are some of their preconceptions? A number of answers come to mind.

"We're a superpower." Instinctive is the idea that the United States is the strongest, the richest, the most generous, and therefore the best. In effect, the United States is today the only superpower, and wields unprecedented influence in geopolitical matters. Even our most earnest students cannot be faulted for thinking that our citizens enjoy privileges in virtually all walks of life. We are a God-fearing nation, imbued with JudeoChristian values. At the same time, we are perceived as lacking in one particular virtue: humility. That does not distinguish us from all other peoples, but it is a common perception others have of us. The potential mix of innocence and unintentional arrogance may constitute a block in the internship candidacy process. Will the tragedy of September 11 or the debacle surrounding Enron and Worldcom bring more balance in our superiority complex, in our conviction that we are impregnable and 
supreme in the conduct of business? In that regard, international education can only help and becomes more important than it has ever been. The right internship program will help foster the right global citizen.

"I speak English, so does everyone else today." The problem may not come up for interns in other English-speaking nations, but it does in a country like France, and in some surprising ways. Nothing is more regrettable than the diminished enrollments in French language classes worldwide despite the official support of France's national language and literature. It is one of the few nations that has a ministry-level policy of exporting and sustaining its language, but alas, with limited effect. Conversely, the American language simply piggybacks on economic forces, and is, quite arguably, an excellent vehicle for modern ideas in the arts and sciences. Having said that, cultivated Europeans take it as a given that their children must speak English and earn that coveted MBA, preferably from a good American University, but, as Europeans, they still define themselves culturally through French-a stunning surprise to France, actually. Be that as it may, in modern-day France, college students speak English remarkably well. They obviously speak their own native language, such that American interns no longer have a competitive edge by bringing to bear their native English-language skills.

"I am computer literate." It does not follow that our overseas-bound students are any more computer literate than their foreign counterparts. French and other European students are also computer literate. Still, American students who specialize in information science are not numerous in enrolling in overseas programs. Their skills would make them competitive for good internships. The same applies for students in science, engineering, and technology who tend to lag behind in enrollments overseas. Any number of reasons has been advanced to explain this phenomenon.

"I am friendly and outgoing." A frequent self-portrait of our students, a conviction that Americans are intrinsically "nice." When Europeans state the unabashed truth about a candidate's accomplishments or competencies, that may often be mistaken for "not being nice." It takes coaching to make our students understand that internship supervisors are very busy people, may not have an instinctively supportive attitude, are not waiting to embrace young Americans, and may make hasty judgments based on what they see and hear. Moreover, these judgments may be based on criteria ranging from specific skills to the way the candidate dresses 
and looks, no matter how sexist or chauvinistic that may appear. Analyzing these dynamics as both personal and cultural phenomena, before and during the internship, must be an integral part of the internship process.

"I pay high tuition." Financing higher education in America is a process most Europeans citizens still have trouble comprehending, even if they admit that their campuses are sorely lacking in space, faculty, and facilities. Still, the notion of paying high tuition is anathema to most Europeans, who are accustomed to "free" education that emanates from a providential state. The sense of entitlement that comes from paying high tuition and fees may give the impression to our candidates that their internships are reserved, that they will have a choice from among several options, and that they will be able to choose the most suitable one, or even reject the less compelling ones. This phenomenon is the most challenging task our faculty and administrators face overseas, namely that one cannot negotiate an internship, or much else for that matter, on the basis of money. A good internship program helps students understand why they are not paid, how they get to do these interesting things, that accepting an intern represents an investment by the internship sponsor in time and patience; that, willy nilly, they are at the bottom of the corporate totem poll, and that interesting assignments are earned, not given. Our internship service lives by a motto: we guarantee nothing, but we try everything.

Fortunately, most of our interns assimilate these difficult lessons in acculturation, learn quickly the mechanisms of the workplace in a foreign setting, and perform well, sometimes exceptionally well, in their internships. They recognize that, in addition to their own expectations, their family's expectations, and their faculty's expectations, they also have to meet the needs and expectations of the company where they will intern. For best results one must adopt a fundamental principle: do not come empty-handed, keep an open mind, and do not leave empty-handed. The following sections address this three-part principle, dwelling particularly on the third. 


\section{Do Not Arrive Empty-Handed}

\section{Career and placement}

Before enrolling in an internship program abroad is a good a time to consult with the college's career-and-placement office, an underutilized resource in a liberal arts institution. Liberal arts majors are increasingly thinking pre-professionally. Pre-med students from liberal arts colleges, already on a pre-professional track, get placed with relative ease in good internships with labs, or with appropriate hospital services.

The rule of thumb goes as follows: the more professional focus a student has, the easier he/she will be placed, and the better the placement will be. Students who are not professionally driven show a tendency to adopt a drop-and-add approach, and are more difficult to place. Whereas the practice of drop-and-add is accepted on home campuses, it has to be suspended once overseas, both in the academic setting and certainly in the professional setting. The opportunity to choose from among a number of options, while second nature to our students, can cause conflict with internship supervisors and fellow students. Students who remain unsure of what they want and what they can bring to the task, who look upon the internship as an experiment "to see if I like it," are adapting a formula for likely disappointment.

\section{Domestic advising}

In the application process, the home adviser can play a major role, first to eliminate any suggestion that the overseas experience constitutes time off from the rigors of campus life, or a break from routines, a time just to travel culturally. It then follows that the faculty must have a priority role in what the student does once overseas, and sign off on any credit-bearing courses and on the internship. The faculty should be able to evaluate the content and objective of a course by having easy access to its description and requirements. Courses overseas should be posted on a well-developed website and updated every semester. It is incumbent on resident directors to retain first-rate instructors and it is equally incumbent on American faculty to relate to their counterparts as peers. 
The problem becomes complicated when students from one college receive academic credit for their majors, others for general education requirements, and others not at all, based on performance in the same course. The problem is most acute when it comes to internships where some institutions grant academic credit and others do not. The issue of academic credit may be approached in terms of vocational vs. avocational internships. We recently added the following text to our literature:

At a time when companies seek candidates for commitments of time longer than is currently the case for the Paris Internship Program (PIP), and in light of increased competition from French and European interns, PIP students need to be aware that their candida$c y$ is evaluated increasingly on previous professional experience andlor theoretical knowledge of a field. It is therefore more sensible to leverage your academic background and enhance your future prospects in a related professional field. The most sought-after interns are those whose faculty advisers are explicitly and directly involved in this process before and after the program and who can sign off on a genuine pre-professional internship rather than on an avocational activity unrelated to the major or to a professional track. The internship supervisor will be more inclined to make an effort and the university and its feeder schools can more legitimately grant academic credit as part of an appropriate validation of the internship. You should therefore make every effort to resist the temptation to "try something new in Paris," but rather build on accumulated knowledge and experience.

We have found that if the above principles are adhered to, the level of foreign-language competency takes on a lesser importance. Language skills then become one of a number of skills, and a decision to accept an intern is more broadly based. When the student brings little or nothing to the task, the responsibilities may remain menial and no one is particularly pleased. More significantly, no university should be placed in a position to grant academic credit in a purely avocational field. A case in point involved a student who had a respectable record as a fledgling chemist. He also was an avid rock music fan and he wanted to explore the "rock scene" in Paris. I presented the dilemma I had in having the university grant academic credit for work done in a rock music recording studio, even if the internship report fulfilled the requirements of a good report. I encouraged 
the student to seek advice from his home-campus faculty adviser. His choice in favor of the rock music studio prevailed on the basis of an interest stated in his application file to the effect that he wanted to explore French rock music once in Paris. His college supported his contention, admitted that it was fodder for thought, and resolved with me that it should be a priority subject of discussion for the future. Fortunately, almost any field of professional activity can be the object of intellectual inquiry, so even an internship with a rock music studio can be successfully shaped into a creditworthy academic project.

Similar situations come up when a student claims, "I have done this before," and insists on investigating a new area. It is unconvincing to a prospective supervisor and has a tendency to delay the process of placement. The fact is "you've never done it Paris, and you've never done it in French." That alone makes the opportunity worth trying. A related situation comes up when a student has nurtured some stereotypical views of life in Paris. "It is the capital of high fashion, therefore I should like to do an internship in fashion." If and when the faculty retains a vested interest in the progress of the intern, the internship will be a success for all concerned. Still, a stronger commitment to faculty-supervised observationand-analysis of the internship experience can make the entire enterprise rewarding both in terms of learning and academic credit. Some colleges grant credit for an internship in a foreign language setting only as a language class registration and not in a particular discipline. Boston University and other universities grant credit throughout the academic disciplines.

\section{Keep an Open Mind}

Keeping an open mind is a virtue that most students would like to ascribe to themselves, even though they arrive heavy-laden with many people's expectations. Parents, best friends, faculty, fellow students left behind, registrars, deans, all have placed a number of expectations on the student who is then asked to take on the challenges of local faculty, directors, internship officers, and internship supervisors. As if it was not already a major conceptual leap to live, study, and work in a foreign setting, often in a foreign language, where it takes five times the normal energies to get trivial tasks accomplished compared with similar tasks in 
the home environment, we also ask the student to keep an open mind.

Still, most students reconcile themselves to the situation where a boot-camp-like quality of life is inevitable, at least initially. How does one keep an open mind in the face of the unknown within a potential internship? That requires a high level of trust in the ability of the local staff, one that reassures the student that the placement recommendation is sound. Many students come with the notion that they want to work only for a company with high name recognition. Big is not necessarily better, in fact it almost never is. And a big-name company may well be a multinational where an elaborate human resource apparatus will set up serious barriers to a timely decision. Additionally, the student may discover that the working language of the company is English, whereas the student expected to practice his French. A good resolution is to find out what smaller, lesser known (at least to the American intern) companies have to offer.

It may, and does, turn out that a student's primary goal is to get the experience of work in a bona fide business environment for the primary purpose of perfecting foreign language skills. The tasks in and of themselves are secondary. That, of course, opens up new possibilities, in ways that could not otherwise be found. Conversely, a journalism major may want to apply for an available internship with the International Herald Tribune, and will have to accept that a major American newspaper in Paris will likely have its employees converse in English. The point is that when the student's proposed internship has met, say, four out of five criteria, it serves no useful purpose to seek one that meets all criteria. Such situations do not exist any more than in real life. Keeping an open mind is obviously a significant lesson in real life.

Our guidelines recommend that students proceed to an interview even if they are not absolutely convinced that it is the right placement for them. Surprises occur, most often good ones. The reverse conditions may also be true. If the placement has a pleasant environment, the supervisor likes the candidate, the candidate likes the supervisor, and the activity lies within the general parameters of the student's professional interests, it is a match. If, on top of that, the internship also becomes contingent on the neighborhood, the length of the commute, or on the prospect of some level of remuneration, then the process has failed. It is important to avoid making a student feel coerced into an internship, but the process is intrinsically complex, there is limited time to see it through, and the many vari- 
ables we mentioned earlier are at play. Happy is the intern who can resolve to accept a viable internship in short order and get on with life, enjoying the many facets of that life in his new home.

The orientation, search, and interview process normally takes place on site. More rarely, students interview and are placed in advance of their arrival in foreign site. In some cases, home faculty have identified foreignbased contacts that help make a match and give the faculty member a greater stake in the process.

\section{Do Not Leave Empty-Handed}

We have long contended that interns must return to their home campuses with a substantial and substantive internship report. In the foreign-language setting, this document may be more limited in length, but it is imperative that it be drafted in compliance with certain disciplinary guidelines, that it follow the precepts of process-writing, under the supervision of a faculty tutor who meets regularly with the intern and supervises the progress of the report and helps the intern assess his/her progress in the company. The supervisor must be formally advised that the intern is scheduled for regular appointments with his faculty tutor and that allowances for that purpose are expected. Similarly, the intern may be scheduled for an oral defense of the report, during which a small jury questions him. This sets the internship report deliberately apart from a journal or diary in which some interns are asked to jot down their impressions and their experiences. The latter often neglect the strictly technical aspect of a professional report and do little to assure an adequate organization of thought or hone presentation skills crucial to a fledgling professional, and fall short of the analytical exercise commensurate with the requirements of the home college or university. Whereas a journal has the student as his own reader, the formal internship report requires an objective reader and helps the intern think in terms of leveraging the experience against further gains in the future. Our Paris interns are advised early on that the report must satisfy the requirements of the jury as to content and form on the occasion of the oral defense. It should be eminently presentable upon return to the home campus to both a professor of French and to a faculty member in the relevant discipline. These standards are not incompatible with the requirements of a prospective employer. 
To that end, universities organize their internship semesters in a variety of ways. Our own Paris Internship Program semester requires that all course work be completed up front during the first eight weeks, so as to devote the second eight weeks to a full-time internship. That is a minimum requirement for being competitive on the internship market, at least in France. Increasingly, companies require longer commitments, at the very least three months, most often four, and increasingly, six. One might want to opt for longer semesters, and focus internships beginning in January and ending in June to provide a minimum of three-and-a-half months for a full-time internship, notably in sectors such as banking and finance, business management, and engineering. It would also make it more likely for interns to extend their stay if and when invited by their supervisors during the summer months, assuming that the company can then cover the cost of a base salary or in-kind support, and thereby foster a better chance at establishing a career track.

Whatever the length of the internship, faculty supervision of the written document should normally aim to include three main components:

1. Data-gathering focusing on the organization of the company, its history, its place on the market, or its mission if it is a not-forprofit corporation;

2. The role of the intern and his/her place in the company or in the department where he/she serves, with a special emphasis on crosscultural issues. These should go beyond the normal assertions of differences in behavioral patterns found in popular books available to most US expatriates on foreign assignments and show evidence of more sustained analysis;

3. A significant issue raised within the context of the internship that requires a modicum of research and reading about a problem of concern to professionals in the field and to society in general, this to insure the academic dimension of the internship.

Various universities and independent agencies provide their own guidelines on what constitutes an internship abroad acceptable for academic credit. The requirements range from part-time, half-days, to full-time assignments as in the case of Boston University's Paris Internship Program. The length of the academic paper may vary from ten pages to 
5,000 words, in English or in the host country language, or a combination of the two. In a certain number of cases, the internship is organized around a weekly workshop or seminar that provides both an organized sequence of subjects, not unlike a regular course, and an opportunity for students to exchange views and experiences in the work place. Ideally, there ought to be both a running seminar and individual tutorials, especially in a foreign language setting, contingent on the time availability of the intern and the requirements of the company, whose needs may vary from week to week.

The weekly seminar may focus on a range of issues: intra-office relations, the notion of service, cultural taboos, the press, public vs. private, avoiding mistakes and pitfalls, culture and ethics, culture and time, multicultural meetings, international negotiation and communication. Students may fill out the Cross Cultural Adaptability Inventory (CCAI) and see how they fare on the scale. Other features may be included in the drafting of the internship report. Grading policy may vary from institution to institution, although the academic analysis component of the report should likely be weighted heavily, as opposed to the other components and the supervisor's evaluation. Our own sampling is offered below. Clearly, the entire enterprise, if it is to meet a maximum of expectations and be a successful college experience, requires a partnership on behalf of the student intern.

\section{Forging a Partnership}

It is important to inform the internship supervisors of your educational policy and give them a stake in the partnership that you forge together in support of professional training. In our case, once the student is accepted and has signed his contractual "convention de stage," the supervisor receives a letter detailing the way the student will meet his obligations on the work place, and with the local faculty with respect to the report. We encourage the supervisor to lend a hand in providing ideas and materials for the enhancement of the report, but ask that the process writing of the report be left to the school-based faculty, especially within the framework of a foreign language, so as to avoid mixed signals regarding style, organization, and rhetorical devices used in the presentation of the materials. Assuming a broad partnership between home-campus faculty 
adviser, the local staff, and the internship supervisor, the student is bound to be well served. We have noted that the writing skills inherent in the drafting of a report have impacted dramatically on the way the student writes thereafter. The student carries back the original edited report with him/her for future leveraging, and leaves a copy in our resource center. That library of past reports helps new students better situate themselves in various fields and to better prepare them for the interview process. There exists ample evidence from our substantial alumni association that our past interns fare remarkably well on the job market. Their candidacies often rise to the top of the pile once the recruiter realizes that they have successfully interned in a company overseas.

\section{A I umni and Long-Term Follow-Up}

No better testimony about an internship program can come than from its own alumni. Accordingly, we have tracked our graduates for the past dozen years and maintain a database of past students through regular correspondence. This alumni network helps us assess the quality of the program, identify areas in need of improvement, capitalize on contacts and assistance from alumni now in decision-making positions, and generally get a sense of the impact internships abroad have on our students. The following samples were gleaned from among this year's respondents who graduated over the past few years. The students are identified here by first name, home college, academic major, locus of internship, semester of enrollment, and a brief summary of activities since completing the internship.

"Spent two years in aviation consulting firm. Moved to Moody's Investors Services as financial analyst. Moved to Fitch IBCA as financial/marketing analyst. Completed an MBA in Marketing and finance at Stern School of Business (NYU)...I have very fond memories of classes with M. T, and Ms. F, and continue to read, write, and speak French as often as possible." Mark S., Boston University, Economics, Fall 1989, Ministry of Industry

"Planet Cybercafé: Graduated in June 2000 from the University of Rochester with an MBA. Will work for Kraft Foods in e-commerce 
marketing in August 2000. PIP belped me to develop my language ability, especially in writing. My internship at Planet Cybercafé was key in my decision to engage in an interactive web project as my senior project in French. PIP was a great program for me because it combined my two majors of French and Economics, something that would have been difficult to do elsewhere. During PIP internship: Initiated clients into the use of cyberspace technology. Assisted in the development of a business and created web pages for it." Jennifer H., Vassar College, French and Economics, Spring 1996.

"Hafslund Nycomed France (Pharmaceutical): PIP helped me in the job search process after college, where I could show that I studied and worked in two different countries. This sounds very impressive to the ears of a job interviewer, especially in such an international corporation." Elizabeth H., Boston University, Business Administration, Fall 1995.

"My stage with Young and Rubicam in Paris gave me my first look at advertising and I would never have been able to work at JWT advertising in Paris after graduation if it wasn't for my $Y$ and $R$ experience. And then I wouldn't have been able to work for JWT in Atlanta if it wasn't for JWT Paris ... and so the story continues. My internship was indispensable." Beth B., University of Georgia, Journalism, Fall 1990.

"During my PIP internship, I was assistant to the head of the communication department. Due to the absence of a colleague, I was entrusted with significant responsibilities in a field dear to me. Secondary benefits included a strong mastery of the French language. Living in New York City and working for CNN." Emma L., Boston University, Art History, Spring 1996, Guy Laroche (fashion).

"Seized the opportunity to work for a consulting firm that specialized in the creation and development of biotechnology start-up companies outside of Clermont-Ferrand...I have decided to open a US branch of Eurobiotic outside of Philadelphia in September 2002, of which I will be the US VP. A West Coast branch is scheduled to open in San Diego 
in 2003." Julie G., University of Pittsburgh, French, Spring 1997, Sherman and Sterling (law office).

"During my senior year at Lafayette, I will be writing an Honors thesis drawing greatly on my experiences in court with Mâtre P. In my search for law schools I have been investigating any abroad opportunities to do further work with a lawyer in France or continue my study of law there. I have also kept in close touch with a number of friends from the program and we see and speak to each other often." Erin R., Lafayette College, Government/Law and French, Fall 2001, Cabinet Juridique PF (small law firm).

Some testimonials exceed the above and point to remarkable achievement for students whose careers have been clearly marked by the internship experience. Some are far more modest. Others still report that the internship at least helped them resolve that they did not want to pursue the original career objectives. And some just plain did not work out, although, admittedly, disappointed students tend not to respond to the alumni inquiry. Conversely, some come from students whom we concluded we failed to serve well and who report surprising success but with considerable delay, such as five or more years later.

\section{Life in the Big City}

The application, orientation, and interview process is intrinsically complex and wrought with many potential obstacles. One stems from the simple fact that, despite the finest means of communication, students do not always follow through on communication, and may fail to read documents, or tend to assume that the content may be relevant to others but surely does not apply to them. Still the process can and does work for an amazingly large percentage of candidates who have proven to be very loyal alumni/ae of the program, with some now in positions of influence and able to recommend current students to their former supervisors or colleagues in the field. There are even a few examples of students returning to work overseas and taking on an intern, soon to be a fellow alumnus. 


\section{Legal Is sues}

The university accepts its obligations, provides significant resources to meet the expectations of its students and their parents, and maintains a high profile in a foreign setting. Still, it must limit its liability. To that end, Boston University's General Counsel drafted a document that may be useful for others to consider. It is reproduced below.

\section{Potentially Dangerous Internship Placement Disclosure}

The location where internship possibilities will be carried out is under the control of the Internship provider-the company, agency, or organization - to which you will be assigned. Many factors may affect the suitability of the assignment location. Since the Program does not control the conditions relating to transportation or to the actual conditions at the particular Internship site, each student is encouraged to review the conditions relating to the safety, or if you require an accommodation at or for getting to the internship relating to disability, you should speak with the Resident Director about your concerns and needs. Where appropriate, adjustments at the worksite or changes in Internship location may be arranged.

\section{Conclusion}

There is overwhelming evidence that an internship abroad ranks high within the area of experiential learning, personally, academically, and professionally. Because of all the requirements of settling, living, and working in a foreign country and the normal wanderlust to explore the country as a visitor, internships abroad need longer and more elaborate preparation from the onset and more substantial support services on site. All parties involved in the student's experience must be made aware of the special conditions inherent in a foreign setting and agree on what are desirable and reasonable objectives. The guiding principle stipulates that a student remains a student and is not an employee, and that college work is first and foremost an intellectual enterprise. This quality is compatible 
with practical training but must supersede it. Internships may differ significantly from place to place, from one area of activity to another, from one company to another. The focus on academic respectability assures an even keel to the way internships work and they way they are evaluated by the students, by the staff, and by the home colleges and universities.

As we move toward a clearer definition of that amorphous concept of globalization, it is relatively simple to see how services, goods, and people will increasingly enjoy free movement. More importantly, we will need to foster the free movement of ideas. Dramatic geopolitical shifts are upon us: the inexorable march of European integration and enlargement, post 9-11 America, the modernization of China, war and peace in the Middle East, the Pan-Islamic world, the bankrupt economies of South America, and the drained resources of Africa, to mention the most obvious ones. International education in general and internships abroad in particular will play an increasingly important role in fostering the free movement of ideas because of the latter's privileged position at the crossroads of university and professional training. Because it involves the student directly at the core of people at work and at leisure, internships abroad may prove to be the most efficient and rewarding ways of learning about another culture and ultimately about one's own, and thereby serve as a key component in the reform of education in all societies. This view from France on behalf of American undergraduates may appear relatively narrow and idiosyncratic since it links two rich Western countries. It is also rich in institutional precedents likely to inform the way higher education will evolve. This view is merely descriptive and in no way prescriptive, and will hopefully contribute to the debate on an important issue among professionals in international education. 


\section{A P P E D I X}

\section{Internship Reality Checklist}

As a matter of professional protocol, you should carry an appointment book and/or calendar with you at all times. It is especially important to note your interviews, class and tutorial schedule, and any group outings.

Internships in Paris are unlike those of other sites. They require varying levels of fluency in French. Most French students do one or more internships as part of the normal process of their education. You compete for assignments with them.

The world economy is in a constant state of change, and unemployment in France remains high. This has a real impact on the process.

Companies may need interns anywhere from three weeks to six months. You are covered for only two months at a designated time.

Evaluate the difference between what your abilities and credentials are and what you wish they were. What appears on your CV may not be considered an adequate credential, no matter how important it seems to you.

Expectations are difficult to meet because you just don't know what it's like to work in France. See this internship first as a means to observe another culture in depth.

Remain open-minded about your options in diverse fields. Don't miss out on an opportunity on the basis of your limited knowledge or experience.

Getting an internship is a two-way transaction, with the emphasis on the firm's willingness to accept you, not the other way around.

Some sectors are more demanding than others. Can you write an article in French for a daily newspaper? Can you perform financial analysis for a bank in French?

It is your responsibility to seek counsel when difficulties on the job arise. Nobody quits without first consulting with the director. Even the greatest adventures don't always feel good. BU headquarters and staff are a resource. Use them accordingly.

You are unlikely to miraculously become a native French man or woman, let alone a good one. But you are unequivocally a foreigner, and can be a good one. Even that comes as a result of significant effort.

Work is not as glamorous as TV series make it out to be. French colleagues can be much different from American ones. For better or for worse.

In some cases one interview will suffice to secure your internship. In other cases, two or more may be required. The key is to answer the company's needs. Before and after obtaining a placement, you must discipline yourself and stop obsessing about the internship.

Is it hard? You bet it is. Is it worth the effort? Unquestionably. See the results from our alumni survey. 